\title{
Divulgação científica e visões deformadas sobre o trabalho científico: contribuições para o ensino de física a partir da análise de textos jornalísticos
}

\author{
Scientific disclosure and deformed views of scientific work: contributions \\ for teaching physics from the analysis of journalistic texts \\ Difusión científica y visiones deformadas sobre el trabajo científico: \\ contribuciones a la enseñanza de la física a partir del análisis de texto \\ periodísticos
}

\author{
Willian Grecillo dos Santos, (willian.grecillo89@gmail.com) \\ Universidade Federal de Santa Catarina-UFSC.
}

\section{Karine Raquiel Halmenschlager, (karinehl@ hotmail.com)} Universidade Federal de Santa Catarina-UFSC.

Resumo: Este estudo tem como objetivo identificar a manifestação de visões deformadas sobre o trabalho científico (PÉREZ et al., 2001) presentes em reportagens que relata o esforço coletivo realizado para a construção da primeira fotografia de um buraco negro, divulgada no ano de 2019. Para isso, foram consideradas cinco reportagens, veiculadas nos principais portais de notícias brasileiros. A análise de tais reportagens foi realizada com base nas sete visões deformadas sobre o trabalho científico discutidas por Pérez et al. (2001), as quais foram consideradas como categorias a priori, de acordo com os princípios da Análise Textual Discursiva (ATD). Entre os resultados, destaca-se que as compreensões relacionadas à visão individualista e elitista, a concepção empírico indutivista e ateórica e a visão exclusivamente analítica foram as mais frequentes nos textos analisados. Isso evidencia, entre outros aspectos, a necessidade de ampliação de discussões sobre a natureza da ciência no contexto escolar, na formação de professores e nos espaços de formação dos profissionais que produzem textos de divulgação científica.

Palavras-chave: ensino de física; visões deformadas do trabalho científico; divulgação científica.

Abstract: This study aims to identify the manifestation of deformed views on scientific work (PÉREZ et al., 2001) present in reports that report the collective effort made to build the first photograph of a black hole released in 2019. For this purpose, five articles published in the main Brazilian news portals were considered. The analysis of such reports was based on the seven deformed views on scientific work discussed by Pérez et al. (2001), which were considered as a priori categories, according to the principles of 
Discursive Textual Analysis (DTA). Among the results, it is highlighted that the understandings related to the individualistic and elitist view, the inductive and atheistic empirical conception and the exclusively analytical view were the most frequent in the analyzed texts. This highlights, among other aspects, the need to expand discussions about the nature of science in the school context, in the training of teachers and in the training spaces of professionals who produce texts for scientific dissemination.

Keywords: teaching physics; deformed visions of scientific work; scientific dissemination.

Resumen: Este estudio tiene como objetivo identificar la manifestación de visiones deformadas sobre el trabajo científico (PÉREZ et al., 2001) presentes en informes que reportan el esfuerzo colectivo realizado para construir la primera fotografía de un agujero negro liberada en 2019. Para ello, se publicaron cinco artículos. considerado, publicado en los principales portales de noticias brasileños. El análisis de dichos informes se realizó a partir de las siete visiones deformadas sobre el trabajo científico discutidas por Pérez et al. (2001), las cuales fueron consideradas como categorías a priori, de acuerdo con los principios del Análisis Textual Discursivo (ATD). Entre los resultados, se destaca que las comprensiones relacionadas con la visión individualista y elitista, la concepción empírica inductiva y atea y la visión exclusivamente analítica fueron las más frecuentes en los textos analizados. Esto pone de relieve, entre otros aspectos, la necesidad de ampliar las discusiones sobre la naturaleza de la ciencia en el contexto escolar, en la formación del profesorado y en los espacios de formación de los profesionales que elaboran textos de divulgación científica.

Palabras-clave: enseñanza de la física; visiones deformadas del trabajo científico; divulgación científica.

\section{INTRODUÇÃO}

No contexto da pesquisa em Educação em Ciências da Natureza são significativos os estudos que discutem questões relacionadas à Divulgação Científica (DC) (CORREIA; DECIAN; SAUERWEIN，2017; OLIVEIRA，2015). Oliveira (2015) realizou o mapeamento de teses produzidas no Brasil entre 2010 e 2012 e verificou, entre outros elementos, que a popularização da ciência engloba, particularmente, duas linhas que a autora denomina "divulgação científica", que contempla relatos de experiência e pesquisa, e "jornalismo científico", que envolve tanto questões relativas à linguagem e forma como as informações são comunicadas quanto ao acesso da 
população acerca do avanço da ciência e da tecnologia. Neste estudo, de forma particular, será abordado o que a autora chama de "jornalismo científico".

A mídia jornalística cumpre um papel fundamental na sociedade contemporânea, no processo de DC, que vai ao encontro de uma maior democratização das informações e uma consequente inclusão da população nas questões de interesse social. Na DC existe a preocupação não somente de informar a população a respeito de novidades sobre desenvolvimento científico e tecnológico, mas também de incluí-la nas pautas que guiam essas áreas, tendo em vista que decisões políticas são determinantes no rumo da produção acadêmica, considerando aspectos de financiamento, infraestrutura e ética.

Assim, a DC se apresenta como o canal de comunicação entre a comunidade científica e a população, tendo como seu fio condutor o portal divulgador e o jornalista que produz o conteúdo. Portanto, a figura do jornalista nessa atividade se torna essencial, considerando sua formação direcionada para a interpretação e comunicação de conteúdos de relevância.

Tendo em vista essas dinâmicas, em consonância com o que debatem Rosa e Auler (2016), é importante destacar que a produção de Ciência e Tecnologia (CT) está longe de ser uma atividade capaz de se desenvolver dentro de uma dimensão que goze de uma suposta neutralidade. Como se fosse possível instrumentalizar seus produtores com a capacidade de se desfazer de todos seus pressupostos para trabalharem de maneira imparcial. Nesse sentido, se a produção de CT não é capaz se desenvolver a partir de uma suposta neutralidade, logo, sua comunicação e divulgação também não estará livre desses aspectos. Então, é razoável assumir que o jornalista, ao produzir materiais de DC, é incapaz de se desfazer de seus pressupostos, levando-os para estrutura de suas produções ao interpretar e comunicar os conteúdos de relevância. Aliás, até mesmo no momento em que uma equipe editorial está selecionando esses conteúdos de relevância, os faz com a influência de seus pressupostos. Deste modo, os materiais de DC tão pouco podem desfrutar dessa suposta neutralidade.

Com base nesses aspectos, também é razoável considerar que esses materiais podem carregar diversos elementos que, discutidos sem as devidas problematizações, podem acabar por reforçar visões deformadas sobre o trabalho científico, as quais foram sistematizadas por Pérez et al. (2001). As discussões desenvolvidas pelos autores Pérez 
et al. (2001), com base nas concepções de professores, vêm balizando análises em diversos contextos, a exemplo de Costa et al. (2017) que investigou visões distorcidas acerca da natureza da ciência em estudos publicados sobre História e Filosofia da Ciência (HFC), a partir de uma revisão em anais de eventos da área. Já Mousinho, Silva e Brandão (2016) fizeram um estudo exploratório sobre a visão de ciência de professores e estudantes.

O estudo das visões deformadas se torna relevante para o campo do Ensino de Ciências da Natureza considerando que estas podem ser reproduzidas no contexto educacional e na DC, sendo apropriadas pela população de forma que se tornem referência para decisões relacionadas às políticas de CT. Nesse sentido, Dagnino (2008), ao discutir a coerência entre os Estudos em Ciência, Tecnologia e Sociedade e as orientações da Política Científica e Tecnológica na América Latina, aponta para uma considerável relação entre essas orientações e o trabalho docente no Ensino de Ciências da Natureza, considerando que a atuação do educador têm grande influência na construção do pensamento das novas gerações que irão, por consequência, determinar as orientações dessas políticas.

Nesse sentido, ganha importância a instrumentalização da população e dos professores em ciências para a realização de uma leitura crítica dos materiais de DC, a partir do trabalho com elementos retirados destes. Neste estudo, de modo particular, o recorte analítico considerou textos jornalísticos relativos a comunicação sobre a construção da primeira fotografia de um buraco negro, divulgada no ano de 2019. A abordagem desse "evento", no contexto específico do Ensino de Física, pode contribuir para diversas discussões, entre elas, a exemplo do estudo publicado por Arenghi e Carvalho (2014), que tomou como ponto de partida da problematização da temática "Agrotóxicos" textos de DC de forma articulada ao contexto dos estudantes, os quais eram oriundos de áreas rurais..

Diante deste contexto, é objetivo deste artigo identificar as visões deformadas sobre trabalho científico que possam estar presentes em reportagens que relatam o esforço coletivo realizado para a construção da primeira fotografia de um buraco negro. Para tal, foram consideradas reportagens veiculadas nos principais portais de notícias brasileiros. Espera-se que as discussões apresentadas neste estudo contribuam, por um 
lado, para ampliar a reflexão sobre como esses materiais podem acabar por reforçar as visões deformadas do trabalho científico. E, por outro lado, colaborem para fomentar discussões que possam auxiliar a superação dessas visões subsidiando processos de formação de professores, tendo em vista que esses profissionais devem estar preparados para a realização de uma leitura crítica desses materiais e tomar consciência de suas contradições para que seja possível discutir e problematizar essas visões.

\section{VISÕES DEFORMADAS DO TRABALHO CIENTÍFICO E O ENSINO DE FÍSICA}

O desenvolvimento do trabalho científico, e também tecnológico, têm suas características e uma delas é estar longe de desfrutar de qualquer tipo de neutralidade social e política (ROSA; AULER, 2016). A própria escolha por programas de pesquisa está condicionada por uma série de pressupostos nutridos por cientistas, políticos e educadores. Porém, para a população em geral, muitas vezes, é transmitida uma ideia de neutralidade da CT, como se as teorias científicas fossem induzidas a partir de observações assépticas da natureza e o trabalho do cientista é simplesmente socializado com o resto da humanidade, sem qualquer responsabilização ou impacto. Esse tipo de equívoco ao se olhar para o ofício da ciência constitui o que Pérez et al. (2001) chamaram de visões deformadas do trabalho científico. Ao trabalhar com grupos de docentes da área das ciências e revisão de literatura científica do campo, o grupo de pesquisadores conjecturou sete visões deformadas sobre o desenvolvimento do trabalho científico, quais sejam:

1) Concepção empírico-indutivista e ateórica: constitui-se de uma valorização da observação e da experiência, desconsiderando os pressupostos teóricos carregados pelos cientistas nos estudos e conferindo ao trabalho científico um caráter de neutralidade.

2) Visão rígida: constitui-se a partir da afirmativa sobre a existência do método científico, único e imutável, com etapas rigorosamente definidas que se seguidas levarão ao resultado. 
3) Visão aproblemática e ahistórica: é a perspectiva de ciência pronta, desconectada de seu processo histórico e dos problemas que discorreram de seu desenvolvimento.

4) Visão exclusivamente analítica: trata-se de uma visão simplista sobre a composição dos programas de pesquisa, os quais derivariam de análises realizadas a partir de uma suposta divisão parcelar dos conhecimentos, ignorando completamente sua historicidade e constituição de correntes de pensamento.

5) Visão acumulativa de crescimento linear: é a ideia de que os conhecimentos científicos evoluem progressivamente de maneira estável e linear durante a história, se acumulando, de forma a ignorar todas suas crises e remodelações.

6) Visão individualista e elitista: é aquela na qual se consideram os conhecimentos científicos como construções exclusivas de sujeitos de altíssimo nível intelectual, em uma forma de trabalho isolado e individual, ignorando a importância das diferentes formas de trabalho científico e da cooperação entre equipes de programas de pesquisa.

7) Visão de neutralidade social da ciência: é a ideia de que a ciência se desenvolve a parte da sociedade e que cientistas são pessoas acima de qualquer valor humano, ignorando as relações políticas e humanas implicadas na produção científica.

Os autores ainda chamam a atenção para o fato de que essas perspectivas não existem de maneira autônoma, ocorrendo uma integração entre as mesmas. Nesse sentido, um material didático, texto de DC ou prática pedagógica pode contribuir para reforçar mais de um desses estereótipos a partir de elementos visuais ou textuais.

Apesar da possibilidade desses elementos serem constituintes de textos de DC, esses materiais são assumidos por professores como importantes recursos para se construir uma mais profunda contextualização dos conteúdos por serem capazes de apresentar a ciência como corpo de conhecimento em construção a partir do relato do trabalho científico. Ainda para Souza e Rocha (2018), com base nas obras de Parkinson e Adendorff, esse tipo de material se torna muito útil para a construção de uma problematização da natureza da ciência, se constituindo a partir de um vocabulário e 
linguagem mais próxima do cotidiano dos estudantes. Estes materiais ganham ainda mais relevância no contexto do ensino a partir de sua inclusão em livros didáticos, como apontam os autores supracitados.

Porém, os textos de DC passam por uma série de processos de adaptação, desenvolvidos por pesquisadores e educadores da área do ensino de ciências, antes de serem incorporados aos livros didáticos. Apesar de essa ser uma prática interessante para a construção de materiais didáticos que serão trabalhados em sala de aula, é fato que o estudante, e, após a escolarização, o cidadão, continuará a consumir conteúdos de DC provenientes dos portais de notícias mais populares, os quais são produzidos por profissionais do jornalismo. Então, é importante incorporar o texto de DC no Ensino de Ciências da Natureza não somente como elemento de contextualização e de forma adaptada, mas também como elemento de uma atividade que contribua para a construção de uma leitura crítica do universo científico, confrontando-o com elementos da história e natureza da ciência, a partir da evidência nesses materiais de elementos como as visões deformadas do trabalho científico.

\section{ASPECTOS METODOLÓGICOS E RESULTADOS}

Para a presente pesquisa, de natureza qualitativa (LÜDKE; ANDRÉ, 1986), foram selecionadas reportagens de DC de cinco portais de notícias mais populares no Brasil, que focalizavam a construção da primeira fotografia de um buraco negro, divulgadas no ano de 2019, as quais são: (R1-G1) Algoritmos que montaram $1^{a}$ imagem de um buraco negro foram criados com ajuda de pesquisadora de 29 anos; (R2-BBC) Como algoritmo criado por jovem cientista possibilitou $1^{a}$ foto de buraco negro; (R3-El País) Assim se 'fotografa' um buraco negro; (R4-Estadão) Em dia histórico, cientistas revelam primeira imagem de um buraco negro; (R5-Gaucha $\mathrm{ZH}$ ) Foto de buraco negro mostra que Einstein estava certo.

A análise foi realizada de acordo com os pressupostos da Análise Textual Discursiva (ATD) (MORAES; GALIAZZI, 2007). O processo da ATD envolve três etapas: (1) unitarização, em que são selecionadas as unidades de significado a partir da fragmentação do corpus de análise; (2) categorização, etapa em que as unidades de 
significados com ideias semelhantes são agrupadas, formando as categorias de análise; e

(3) comunicação, momento em que, com base no material analisado, são construídos metatextos descritivos e interpretativos acerca do objeto de pesquisa. As categorias podem ser a priori, oriundas da literatura, ou a posteriori, obtidas por meio dos dados analisados. Na presente pesquisa, as visões deformadas discutidas por Pérez et al. (2001) foram consideradas categorias a priori.

Dessa forma, os textos selecionados foram analisados objetivando selecionar e categorizar trechos que possam contribuir, em algum nível, para reforçar as visões deformadas do trabalho científico. A análise das reportagens evidenciou que dentre as sete categorias analíticas consideradas, todas foram contempladas por trechos extraídos dos textos de DC, sendo: (i) concepção empírico indutivista e ateórica contemplada pelas R1, R2 e R3; (ii) visão rígida contemplada pela R5; (iii) visão aproblemática e ahistórica contemplada pela R3; (iv) visão exclusivamente analítica contemplada pelas R1, R2 e R4; (v) visão acumulativa de crescimento linear contemplada pela R2; (vi) visão individualista e elitista contemplada pelas R1, R2, R4 e R5; (vii) visão de neutralidade social da ciência contemplada pelas R1 e R3. Na sequência os resultados serão discutidos a partir das categorias analíticas.

\section{(i) Concepção empírico indutivista e ateórica}

Esta está entre as mais presentes nas reportagens analisadas. Isso se justifica, pois, os textos apresentam um esforço no sentido da construção de uma relação entre pesquisadores e problemas de pesquisa em uma forma isolada de seus elementos contextuais, deixando de lado os processos históricos e colocando todo o peso das construções teóricas sobre os dados coletados. O trecho abaixo extraído da reportagem do G1 demonstra esse aspecto.

Depois de obtidos os sinais, a montagem da imagem leva em conta outras variáveis. Isso porque os pesquisadores fizeram uma suposição de como seriam as imagens dos espaços vazios que não foram captados pelos radiotelescópios. Para contornar mais esse obstáculo, Bouman aplicou a aprendizagem de máquinas para identificar padrões visuais que tendem a ocorrer nas imagens reais e, depois, refinar o algoritmo para reconstruir imagens. (R1-G1, 2019, p. 1). 
Ao ignorar os processos dos desenvolvimentos teóricos e conceituais pelos quais a concepção de buraco negro passou durante a história do campo de pesquisa no século $\mathrm{XX}$, esse trecho tende a expressar um ideário em que os pesquisadores envolvidos nesse projeto construíram suas hipóteses de forma isolada desse contexto histórico-social. Ainda mais, considerando que a emergência dessas hipóteses não é simplesmente baseada nos dados produzidos pelos radiotelescópios, mas sim se trata de uma estimativa construída a partir da articulação entre esses dados e conjecturas teóricas do campo de pesquisa para a imagem do buraco negro.

O trecho a seguir, extraído da BBC, por sua vez, muda de foco, pois, em vez de expressar a visão deformada a partir da relação entre pesquisador e dados, a expressa através da relação entre dados e métodos.

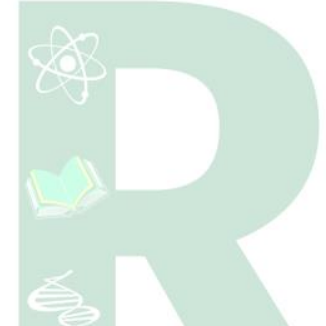

Como indica a legenda de Katie, "fotografar" um buraco negro é um longo processo de várias etapas - que inclui desde usar complexas fórmulas matemáticas a lidar com ruídos vindos do espaço. "Assim como um artista forense usa descrições limitadas para formar uma imagem usando seu conhecimento sobre o formato do rosto, os algoritmos de imagem que eu desenvolvi usam nossos dados limitados de telescópios para compor uma imagem”, explicou a jovem no TEDxBeaconStreet. (R2-BBC, 2019, p. 1)..

Ao dar ênfase as equações matemáticas contidas nos algoritmos construídos para o tratamento das interferências nos sinais detectados pelos radiotelescópios, o escritor deixa de abordar diversos aspectos contidos em todos os processos de construção teórica que basearam a matemática contida nesses algoritmos. Esse tipo de expressão desenha uma visão de trabalho científico baseada na emergência conceitual a partir de dados, em que a figura do cientista se limita somente a de um mediador entre teoria e dados.

Já outro trecho, extraído da Gaúcha ZH, expressa ideia semelhante ao fragmento da BBC, porém, agora concentrado na figura dos equipamentos de análise dos dados.

Primeiro, apontaram para a mesma direção, ao mesmo tempo, e capturaram um fragmento do buraco negro de um ângulo diferente (por estarem posicionados em partes diferentes do planeta Terra). Em seguida, cada "pedaço" de radiação foi enviado a um supercomputador, que uniu os fragmentos e os converteu em imagem - um processo semelhante ao qual um aparelho de televisão realiza. O projeto ambicioso ganhou o nome de Event Horizon Telescope (EHT), ou Telescópio de Horizonte de Eventos. (R5HARTMANN, 2019, p. 1). 
Nesse trecho, o escritor apresenta a ideia de um "supercomputador", no qual o cientista insere os dados e os resultados são exteriorizados. Tanto no fragmento apresentado como no restante do texto não há nenhum destaque para a figura do cientista, seus pressupostos e nem os processos teóricos de formulação e construção pelos quais os equipamentos, métodos e conceitos passaram.

As compreensões expressas nesses trechos são problemáticas no sentido de que tendem a ignorar a figura central na produção científica de conhecimento, o ser humano cientista, a qual constrói o corpo teórico a partir de processos altamente dinâmicos como debates, coletivização de experiências, estudos de correntes de pensamentos de programas de pesquisa concorrentes, erros e reconstruções, visões de mundo e espiritualidade humana. Esse tipo de visão sobre o trabalho científico apresenta um pesquisador que seria responsável somente pela extração dos dados da natureza, e montagem da teoria como um suposto quebra cabeças de dados.

\section{(ii) Visão rígida}

Apesar desta ser uma das mais discutidas na literatura, e que o debate sobre a pluralidade de métodos para se fazer ciência vem se destacando, apenas uma reportagem apresentou elementos que contribuíram para reforçá-la. O fragmento abaixo, extraído da Gaúcha ZH, apresenta, além de erros conceituais em relação as definições de alguns elementos científicos, uma concepção de ciência engessada em uma maneira de desenvolvimento.

\footnotetext{
Vale lembrar que, na ciência, "Teoria" ou "Teorema" não significam hipótese ou probabilidade, mas "lei científica". Só não há o nome de "lei" por certa humildade da ciência: a tecnologia da humanidade pode, um dia, permitir uma nova descoberta que muda a concepção que havia sobre determinado tema - pense, por exemplo, no interstício, órgão descoberto no corpo humano apenas no ano passado, após o avanço da tecnologia. Quando uma tese é proposta à comunidade acadêmica, sofre análises minuciosas. Se mesmo assim resiste forte, ganha, como prêmio, o nome de teoria ou teorema. Einstein sobreviveu às investigações e agora, mais uma vez, é reconhecido por sua genialidade. (R5-HARTMANN, 2019, p. 1).
}

Ao descrever os passos pelos quais a construção do conhecimento científico se desenvolve, o texto reforça o imaginário de que a ciência possui um método único para se fazer. Essa série de passos, baseados na premissa da falseabilidade dos 
conhecimentos científicos, não está de acordo com o que acontece na realidade e, apesar de em alguns casos realmente funcionar assim, nem mesmo a produção da foto do buraco negro, que é relatada na reportagem, se deu nessas etapas.

\section{(iii) Visão aproblemática e ahistórica}

O trecho separado abaixo, extraído do portal de notícias ElPaís, possui elementos que reforçam a visão aproblemática e ahistórica sobre o trabalho científico e foi o único selecionado dentro do corpus. Ao se concentrar apenas nos dados de radiotelescópios e na expectativa dos cientistas envolvidos no projeto, o texto deixa de lado todo processo histórico, o qual contou com o envolvimento de diversos grupos de cientistas e episódios políticos e sociais, que deram origem e fundamentaram as concepções e teorizações em relação aos buracos negros, estampando uma imagem de ciência desvinculada das problemáticas que guiam seu percurso.

Isto é o que o projeto Telescópio Horizonte de Eventos alcançou. Unindo
telescópios espalhados pelo mundo, uma técnica conhecida como
interferometria, é possível somar os dados de oito radiotelescópios para
simular um supertelescópio tão grande como a separação entre as antenas,
isto é, o tamanho do nosso próprio planeta. Mesmo assim, a partir da foto do
buraco negro temos apenas alguns dados, como se tivéssemos somente
informações de algumas dezenas de pixels ou pontos de uma foto de
milhares. O restante da fotografia deve ser construído entre a combinação de
dados conhecidos e o que esperamos ver. (R3-TOSAR, 2019, p. 1).

Ainda, esse tipo texto não seria tão problemático se a questão do que se espera ver em uma foto de um buraco negro fosse contextualizada e problematizada. Um exemplo que não está no texto e poderia contribuir para uma visão mais realista do trabalho científico é construir uma qualificação desse "esperamos ver", apresentando aspectos como construções teóricas que antecedem o trabalho relatado, os sujeitos e coletivos que passaram por esses processos e as principais questões do campo de pesquisa que, de alguma forma, guiaram as pesquisas até esse momento histórico.

(iv) Visão exclusivamente analítica

Apesar de Pérez et al. (2001) apontarem essa como uma das menos investigadas e também como uma das menos expressadas pelos professores (sujeitos entrevistados no 
estudo referido), foram selecionados três trechos em três reportagens que contém elementos que contribuem para reforçá-la. Abaixo os trechos selecionados.

Como os buracos negros estão muito longe da Terra, não é possível simplesmente tirar uma foto deles com uma lente poderosa. Superar essa dificuldade exigiria montar a imagem usando várias partes, obtidas pelos radiotelescópios disponíveis. Assim, o time juntou oito radiotelescópios ao redor do planeta e aplicou uma técnica chamada interferometria, que combina os sinais captados pelos telescópios. (R1-G1, 2019, p. 1).

Agora, Bouman espera que sua equipe possa prosseguir com a realização de vídeos dos buracos negros - que, eventualmente, podem revelar outros aspectos físicos, como os campos magnéticos nestes objetos. Em seu currículo, a cientista diz também trabalhar para que "métodos computacionais expandam as fronteiras para a geração de imagens interdisciplinar". (R2BBC, 2019, p. 1).

A imagem mostra um círculo escuro no meio de um disco resplandecente. A observação utilizou a capacidade combinada de oito observatórios situados em algumas das regiões mais inóspitas do planeta, como o deserto do Atacama, o topo de um vulcão dormente no Havaí, e até mesmo o polo Sul. "Vimos o que parecia ser impossível de ver", comemorou Shep Doeleman, astrônomo do Centro de Astrofísica Harvard-Smithsonian e diretor do grupo responsável pela captura da imagem. (R4-ROJAS, 2019, p. 1).

Estes possuem um elemento em comum: a ênfase que os escritores dão as técnicas aplicadas aos dados ou, ainda, como os dados podem "revelar" novos conhecimentos acerca dos fenômenos. Essa concentração em torno dos dados não seria tão problemática caso fosse articulada a elementos da HFC e, até mesmo, as situações concretas sobre o trabalho dos cientistas. Um exemplo de contextualização seria discutir o acúmulo teórico e a necessidade de trabalho em grupo para se alcançar os resultados. Ou seja, o problema aqui não é discutir acerca da importância dos dados para a obtenção dos resultados, e de fato eles são, porém, ao dar ênfase as técnicas e aos dados sem qualquer forma de contextualização do trabalho dos cientistas os autores passam a ideia de um desenvolvimento científico no qual o conhecimento "surge" dos dados, a partir de uma mera análise ou aplicação de técnica.

\section{(v) Visão acumulativa de crescimento linear}

Em dois fragmentos a ideia de que o trabalho científico se dá de forma acumulativa é expressa, dando a entender ao leitor que cada passo na construção do conhecimento é antecedido pelo outro e que esse processo se dá de forma linear, conforme evidenciam os trechos a seguir. 
Há mais de um século, Albert Einstein publicou pela primeira vez sua teoria da relatividade. Desde então, cientistas forneceram muitas evidências para sustentá-la. Mas uma das coisas previstas em sua teoria, os buracos negros, ainda não foram observados diretamente", explicou Bouman em 2016 durante uma palestra no evento TEDxBeaconStreet. (R2-BBC, 2019, p. 1).

No Twitter, o MIT comparou a cientista com Margaret Hamilton, também pesquisadora da instituição que escreveu códigos que ajudaram a colocar o homem na lua. A postagem coloca fotos das duas lado a lado: à esquerda Bouman com pilhas de discos rígidos de dados da imagem do buraco negro e, à direita, Hamilton, com o código que ela escreveu. (R2-BBC, 2019, p. 1).

No primeiro trecho a ideia de linearidade do conhecimento científico se dá a partir do status de confirmação que é dado aos trabalhos realizados no campo de pesquisa em questão após a relatividade geral de Albert Einstein. Ou seja, que os trabalhos desenvolvidos nesse campo, inclusive a foto do buraco negro, servirão de comprovação da teoria do físico alemão de forma a ignorar toda a riqueza cultural envolvida na produção dessa fotografia.

O segundo trecho apresenta a ideia a partir da comparação entre dois eventos históricos envolvendo duas cientistas e ressaltando as diferenças tecnológicas, passando a ideia de evolução científica e tecnológica. Essa ideia de desenvolvimento de CT linear, que sempre haverá progresso à medida que o tempo passa, pode parecer verdadeira quando se é analisado um período mais curto da história, porém, ao ser ampliado o olhar sobre o desenvolvimento científico-tecnológico ela se demonstra profundamente falsa. Isso porque os programas de pesquisa desenvolvem disputas culturais ao longo da história, resgatam ideias e elaboram reformulações.

A problemática que se origina, dessa visão acerca do trabalho científico, é focaliza em um mito acerca das relações entre Ciência, Tecnologia e Sociedade (CTS), o qual Auter (2007, p. 8) denominou de "modelo tradicional/linear de desenvolvimento". Esse modelo concebe uma relação CTS em uma forma linear, em que "o desenvolvimento científico (DC) gera desenvolvimento tecnológico (DT), este gerando o desenvolvimento econômico (DE) que determina, por sua vez, o desenvolvimento social (DS - bem-estar social).” (AULER, 2007, p. 8), sendo essa lógica, de acordo com o autor, contraditória à realidade. Assim, os impactos da CT no mundo transpassam os limites da noção de "bom uso" dos produtos tecnológicos. Ou seja, o que determina o impacto social e ambiental de tal campo científico-tecnológico são fatores presentes tanto na pré-produção como na pós-produção de CT, ligados a aspectos geopolíticos, 
conforme apontam Delizoicov e Auler (2011). Uma maneira de iniciar a problematização desse mito é tratar o trabalho científico de forma sincera, debatendo seus momentos de crise e reformulações e, assim, construindo uma ideia de desenvolvimento mais humanizada.

\section{(vi) Visão individualista e elitista}

Esta é a mais presente nas reportagens, expressando um foco dos textos sobre os cientistas, numa forma individualista, destacando aspectos de genialidade $\mathrm{e}$ diferenciação. Ao todo foram selecionados dez trechos entre as cinco reportagens, sendo quatro do G1, dois da BBC, um do Estadão e três da Gaúcha ZH.

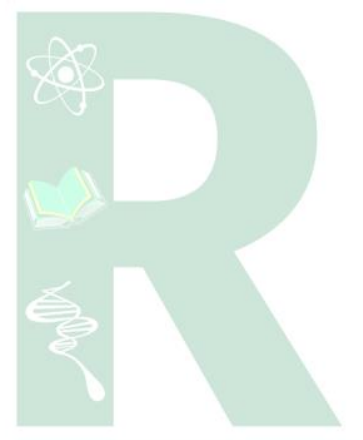

A pesquisa dela com a aprendizagem de máquinas e os algoritmos providenciou aos astrônomos do projeto as informações que os radiotelescópios não eram capazes de captar no espaço. (R1-G1, 2019, p. 1).

Algoritmos que montaram $1^{\text {a }}$ imagem de um buraco negro foram criados com ajuda de pesquisadora de 29 anos. (R1-G1, 2019, p. 1).

Formada em engenharia elétrica e ciência da computação pelo Massachussets Institute of Technology (MIT), nos Estados Unidos, Bouman tem 29 anos, segundo o jornal "The Washington Post", que a entrevistou na tarde desta quarta após sua foto de perfil viralizar na internet. (R1-G1, 2019, p. 1).

A solução encontrada pela pesquisadora americana considera que, se as medidas de três telescópios forem multiplicadas, os atrasos nos sinais deles podem ser cancelados uns dos outros. (R1-G1, 2019, p. 1).

É possível evidenciar que estes trechos se concentram na figura de uma das pesquisadoras envolvidas no projeto. Ao citar aspectos como a influência de trabalhos anteriores, a autoria sobre os algoritmos que remontaram a imagem e o quão jovem a pesquisadora é, fica evidente a caracterização de uma ciência feita por poucos, de maneira solitária e genial. Isso fica ainda mais explícito quando aspectos como a coletividade que envolveu o projeto, o qual contou com a colaboração de 68 instituições pelo mundo e que a pesquisadora faz parte de uma das três equipes que trabalharam na construção do algoritmo, ficam de fora.

Como algoritmo criado por jovem cientista possibilitou $1^{\mathrm{a}}$ foto de buraco negro. (R2-BBC, 2019, p. 1).

Por trás da histórica imagem de um buraco negro divulgada ao mundo nesta quarta-feira estão anos de trabalho de uma jovem cientista americana que liderou a criação de um algoritmo fundamental para esta mais nova conquista da ciência. (R2-BBC, 2019, p. 1). 
Uma personagem importante da descoberta foi a jovem Katherine Bouman, de 29 anos, estudante de pós-doutorado no Centro de Astrofísica HarvardSmithsonian. Foi ela que desenvolveu o algoritmo que montou a imagem divulgada nesta quarta. Para isso, trabalhou no projeto nos últimos seis anos. Ela foi uma entre os 30 cientistas que processaram os dados reunidos pelo Telescópio do Horizonte de Eventos. (R4-ROJAS, 2019, p. 1).

Como pode ser observado nos trechos acima, as reportagens dos portais de notícias BBC e Estadão vão na mesma linha que a do G1. Já os trechos apresentados abaixo demonstram como a reportagem do Gaúcha $\mathrm{ZH}$ reforça essa visão, porém, se concentrando na figura do físico alemão Albert Einstein.

Foto de buraco negro mostra que Einstein estava certo. (R5-HARTMANN, 2019, p. 1).

Registro comprova teoria de físico alemão e dá mais um passo para a compreensão do surgimento de estrelas e para a investigação do espaço sideral. (R5-HARTMANN, 2019, p. 1).

A importante descoberta agitou a comunidade científica mundial por uma série de motivos: comprova uma teoria desenhada no século passado pelo gênio Albert Einstein, mudará livros de ciência escolares e abre alas para uma miríade de novas pesquisas envolvendo planetas, estrelas e galáxias. (R5HARTMANN, 2019, p. 1).

Ao se concentrar em termos e frases que remontam a importância da fotografia para as teorias de Einstein, que de fato existem mas não se limita a isso, o escritor reforça a visão de que o trabalho científico neste empreendimento se deu de maneira meramente comprobatória das contribuições realizadas pelo físico alemão a mais de um século. Não obstante, no restante do texto não há nenhuma menção sobre a importância do acúmulo científico que se deu durante os processos que culminaram na fotografia e como esses acúmulos problematizam novos aspectos da natureza.

Como se demonstra no recorte feito a partir de reportagens de portais de notícias, essa visão é uma das mais impregnadas nos discursos sobre o trabalho científico. Ainda, pensando em nossas vivências como cientistas em física, é comum escutar como nossos cursos de graduação são difíceis e como os sujeitos que seguem essa carreira precisam ser dotados de intelectos acima da média observada na sociedade.

Há vários aspectos que podem ser problematizados relacionando esses discursos e seus efeitos sobre a produção científica. Um deles pode ser a falta de interesse de estudantes do nível básico de se engajar em uma carreira científica, dadas as condições iniciais que são necessárias, como a genialidade. Outra, pensando em maior profundidade, é que o poder executivo, administrador da sociedade de forma geral, 
também é impregnado por esse discurso e, sendo este determinante para as políticas de CT, o carregará em suas decisões, se tornando uma problemática significativa no que diz respeito a formação do corpo de trabalhadores da CT e a constituição da comunidade intelectual do país.

\section{(vii) Visão de neutralidade social da ciência}

Por fim, curiosamente, esta não esteve tão presente nas reportagens, sendo separado somente dois trechos. Um deles retirado do portal de notícias G1:

Gastamos uma quantidade enorme de tempo garantindo que o que estávamos vendo era de fato real, e não só algo que, mesmo inconscientemente, a gente pode ter imposto aos dados. (R1-G1, 2019, p. 1).

É perceptível, no fragmento destacado, a divisão que é feita entre os dados e as expectativas dos cientistas. Na produção científica, de fato, há um distanciamento entre os dados e sujeito durante a análise, porém suas expectativas em relação ao processo possuem influências sobre o resultado. Ainda, por trás de uma construção como essa há todo um processo histórico de produção de conhecimento impregnado com as expectativas e credos de uma comunidade de cientistas que são seres humanos, com uma vida social como a de qualquer outro. Essas narrativas tendem a construir uma ideia de separação entre pressupostos sociais dos cientistas e objetos científicos construídos.

No outro trecho abaixo, do ElPaís, a palavra "contamine" é usada para se referir às expectativas dos cientistas sobre a fotografia.

Com um software especial, a imagem é composta com base nos dados recebidos e no que se espera ver nas simulações. Claro que, para evitar que a referência "do que podemos esperar ver" contamine muito o algoritmo, são incluídos elementos de controle, alguns tão curiosos como as imagens do Facebook de Katie Bouman, do projeto EHT. (R3-TOSAR, 2019, p. 1).

Assim, o fragmento acaba por reforçar a visão de neutralidade social da ciência ao dar ênfase a separação entre cientistas e resultados, utilizando o verbo contaminar para denotar um aspecto negativo sobre a influência dos pressupostos teóricos dos sujeitos.

Essa ideia é problemática, pois, uma visão que separa trabalho científico de seus aspectos sociais, pode contribuir para um silenciamento do debate sobre a produção científica. Esse silenciamento se traduz em aspectos como: uma confiança mítica no 
progresso científico-tecnológico; alienação da população em geral para impactos sociais e ambientais das tecnologias; constituição de barreiras que impedem a participação popular no debate da produção de CT, tanto na pré-produção como na pós-produção; e um afastamento entre comunidade científica e população.

Possibilidades para o ensino de física

Apesar de todos esses aspectos encontrados nesses cinco textos, ainda seria muito difícil construir uma prática pedagógica sem a utilização dos materiais de DC, pois esses textos continuarão a serem produzidos e, inevitavelmente, consumidos pela população em geral, incluindo os estudantes da EB. Portanto, incluir esse tipo de material nas atividades didáticas relacionadas ao Ensino de Ciências da Natureza, e demais campos disciplinares como a física, se torna fundamental para a construção de uma prática pedagógica capaz de contribuir para a formação integral dos sujeitos, de forma a objetivar sua cidadania plena. Além disso, incluir essas discussões no ensino se torna fundamental para contribuir com a superação dessas visões deformadas sobre o trabalho científico.

Nesse sentido, Correia, Decian e Sauerwein (2017) ao discutir sobre o trabalho com textos de DC em atividades didáticas para o Ensino de Física apontam para um direcionamento das pesquisas em educação em ciências que demonstram alguns aspectos observados nos estudantes, como um aumento das habilidades de leitura crítica e capacidade de se posicionar frente a problemáticas relacionadas a esses textos em aulas de física. Para as autoras:

[...] a utilização de TDC em aulas de Física pode propiciar discussões entre professor e alunos que envolvam não só a vinculação entre o conteúdo científico ensinado e seus aspectos sociais, políticos, ambientais, históricos e tecnológicos, mas também promover o desenvolvimento de habilidades relacionadas às expressões oral e escrita necessárias à formação do cidadão crítico capaz de se posicionar e argumentar sobre o que lê. Aspectos esses necessários à formação do bom leitor e que, no entanto, nem sempre são trabalhados nas aulas de Física. Como trabalhar um texto de divulgação científica no ensino de ciências? (CORREIA; DECIAN; SAUERWEIN, 2017, p. 2017).

As autoras supracitadas trabalharam com textos de portais como G1 e Estadão durante a realização da regência de estágio curricular em uma disciplina de física. 
Foram desenvolvidas atividades que envolveram ações de pré-leitura, leitura e pósleitura com os estudantes, entre elas: questões iniciais de problematização, proposição de um problema aos estudantes, estruturação de questionamentos pelos estudantes sobre o texto, discussão das temáticas apresentadas nos textos, resolução de problemas, seminários, construção de resumos pelos estudantes e proposição de novas problemáticas pelos estudantes após a leitura do texto. Ainda, Colpo (2019) destaca a importância de se sistematizar a prática da leitura de Textos de Divulgação Científica, no âmbito da educação básica, no sentido de orientar essa leitura para um caráter crítico e questionador.

Nesse sentido, os elementos apresentados nesses estudos, como também as reportagens analisadas, podem contribuir para a construção de atividades didáticas orientadas para a construção de uma leitura crítica em sala de aula. O educador pode utilizar as reportagens para uma primeira leitura e levantamento de questões acerca do trabalho científico e posteriormente separar as visões deformadas e discuti-las com os estudantes na forma de diálogo. Após esses diálogos, podem ser propostos trabalhos aos estudantes na forma de relatórios, questionamentos ou seminários.

Outra opção é a estruturação de atividades pedagógicas pautadas em temas a partir dos pressupostos educacionais relacionados ao movimento Ciência, Tecnologia e Sociedade (CTS) (STRIEDER, 2012). Com objetivos como: i) proporcionar um Ensino de Ciências da Natureza que permita ao estudante enxergar a própria realidade a partir dos conhecimentos científicos; ii) desenvolver nos estudantes um senso crítico, de maneira que eles possam discutir com propriedade as implicações da CT na sociedade; iii) capacitar os estudantes para que eles tomem atitudes de maneira a mudar a própria realidade, essa perspectiva se torna compatível com o que se espera de um trabalho com textos de DC a partir dos referenciais expostos nesse estudo.

Portanto, o trabalho com temas também surge como possibilidade nessa proposta, considerando que temáticas da contemporaneidade no Ensino de Ciências da Natureza podem ser problematizadas a partir de materiais de DC. Sendo que essa etapa problematizadora pode ser composta por uma atividade de leitura e apontamento das visões deformadas sobre o trabalho científico, de forma a reconhecer seus impactos nas 
políticas de CT, destacando sua dimensão social e contribuindo para a desconstrução de uma perspectiva de neutralidade da CT.

\section{CONSIDERAÇÕES FINAIS}

A partir da análise realizada é possível inferir que, pelo menos, uma das sete visões deformadas acerca do trabalho científico, discutidas por Perez et al. (2001), se fez presente na maioria das reportagens consideradas. Sobressaíram-se, contudo: a visão individualista e elitista, evidenciada em quatro reportagens; a concepção empírico indutivista e ateórica e a visão exclusivamente analítica, presentes em três textos.

Isso mostra, também, a necessidade de se pensar na formação dos profissionais que produzem esses textos, pois, formar jornalistas que produzam materiais com uma fidelidade maior ao que de fato é o trabalho de produção de CT é elemento importante para desfazer essas visões deformadas. E, de modo mais amplo, evidencia a necessidade de problematização, no contexto escolar, acerca da natureza das ciências como forma de construir, junto à população, uma imagem adequada sobre o trabalho científico. Assim, é possível síntetizar um objetivo educacional em relação ao trabalho com materiais de DC, seja no formato textual ou audiovisual, o qual iria ao encontro de uma formação para a "cidadania científica", como destaca Delabio et al. (2021) ao discutir e problematizar a percepção dos brasileiros sobre a produção de CT a partir de materiais de DC.

Diante disso, considera-se que o trabalho em sala de aula com materiais de DC é essencial para tratar desses aspectos sobre o trabalho científico. Esses materiais devem estar associados com elementos da HFC, bem como considerar seus aspectos sociais, levando em conta o desenvolvimento científico e tecnológico da humanidade.

Nesse sentido, um dos desdobramentos dessa discussão seria a construção de uma prática pedagógica no Ensino de Física que contemple elementos sobre a natureza da ciência, considerando seus processos históricos e vertentes filosóficas. Deixar esses conteúdos relacionados a ciência de fora da formação básica dos sujeitos se configura como um dos principais aspectos que contribuem para a proliferação de imagens distorcidas sobre o trabalho científico. Nessa perspectiva, também entende-se como 
fundamental tanto a inclusão de discussões de cunho epistemológico na formação inicial de professores quanto a problematização sobre o uso de materiais de DC.

Por fim, sinaliza-se que o Ensino de Ciências da Natureza, e menos ainda o Ensino de Física, não devem ter a pretensão de dar conta de todas essas discussões, e nem seria possível. Então, a construção dessas práticas podem ser potencializadas por meio da promoção de um ensino interdisciplinar, colaborando e se complementando com discussões de outras áreas. São pertinentes, portanto, pesquisas que permitam uma análise e compreensão mais ampla sobre as contribuições de propostas interdisciplinares para a construção de uma imagem mais adequada do trabalho científico.

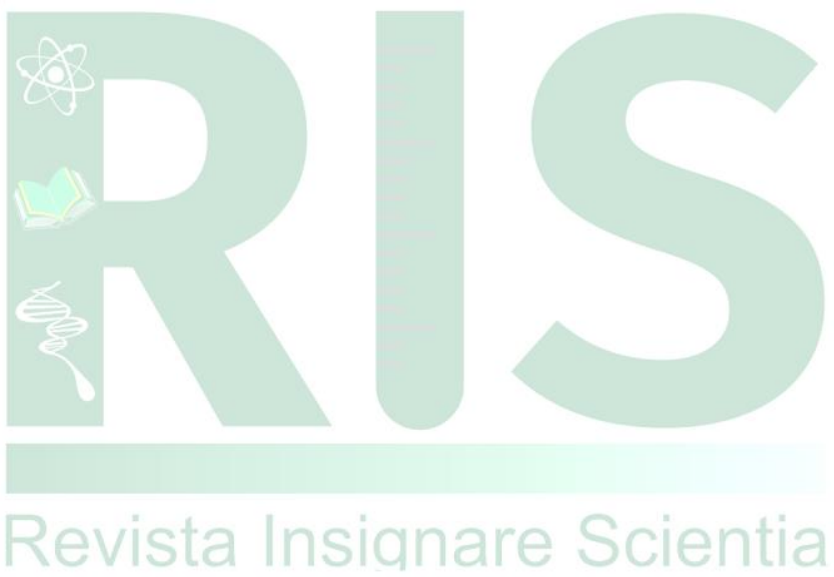




\section{REFERÊNCIAS}

ARENGHI, L. E. B.; CARVALHO, M. L. O. O desafio de se ensinar modelos atômicos a partir do tema agrotóxico: possibilidades de formação problematizadora. Revista tecné, episteme y didaxis. n. extraordinário, p. 30-35, 2014.

AULER, D. Enfoque Ciência-Tecnologia-Sociedade: pressupostos para o contexto brasileiro. Ciência \& Ensino. v. 1, n. esp, p. 1-20, 2007.

BBC. Como algoritmo criado por jovem cientista possibilitou $1^{\mathrm{a}}$ foto de buraco negro. . BBC News Brasil. 2019. Disponível em: https://www.bbc.com/portuguese/geral47886045. Acesso em: 29 jun. 2019.

BUENO, W. C. Comunicação científica e divulgação científica: aproximações e rupturas conceituais. Informação \& informação. v. 15, n. esp, p. 1-12, 2010.

COLPO, C. C. Estratégias de leitura de textos de divulgação científica e a constituição docente de uma professora de química. Revista Insignare Scientia. v. 2, n. 3, 2019.

CORREIA, D.; DECIAN, E.; SAUERWEIN, I. P. S. Leitura e argumentação: potencialidades do uso de textos de divulgação científica em aulas de Física do ensino médio. Ciência \& Educação (Bauru). v. 23, n. 4, p. 1017-1034, 2017.

COSTA, F. R. S.; ZANIN, A. P. S.; OLIVEIRA, T. A. L.; ANDRADE, M. A. B. S. As visões distorcidas da natureza da ciência sob o olhar da história e filosofia da ciência: uma análise dos anais dos ENEQ e ENEBIO de 2012 e 2014. ACTIO: docência em ciências. v. 2, n. 2, 2017.

DAGNINO, R. As trajetórias dos estudos sobre ciência, tecnologia e sociedade e da política científica e tecnológica na ibero-américa. Alexandria: revista de educação em ciência e tecnologia. v. 1, n. 2, 2008.

DELABIO, F.; CEDRAN, D. P.; MORI, L.; KIORANIS, N. M. Divulgação científica e percepção pública de brasileiros(as) sobre ciência e tecnologia. Revista Insignare Scientia. v. 4, n. 3, 2021.

DELIZOICOV, D.; AULER, D. Ciência, Tecnologia e Formação Social do Espaço: questões sobre a não-neutralidade. Alexandria Revista de Educação em Ciências e Tecnologia. v. 4, n. 2, p. 01-27, 2011.

G1. Algoritmos que montaram $1^{a}$ imagem de um buraco negro foram criados com ajuda de pesquisadora de 29 anos. G1: o portal de notícias da Globo. 2019. Disponível em: https://g1.globo.com/olha-que-legal/noticia/2019/04/10/algoritmos-que-montaram-1aimagem-de-um-buraco-negro-foram-criados-com-ajuda-de-pesquisadora-de-29anos.ghtml. Acesso em: 29 jun. 2019. 
HARTMANN, M. Foto de buraco negro mostra que Einstein estava certo; entenda.

Gaúcha ZH. 2019. Disponível em:

https://gauchazh.clicrbs.com.br/tecnologia/noticia/2019/04/foto-de-buraco-negromostra-que-einstein-estava-certo-entenda-cjubpywm7010t01rtl3hnebsk.html. Acesso em: 01 jul. 2019.

LÜDKE, M.; ANDRÉ, M. E. D. A. Pesquisa em educação: abordagens qualitativas. São Paulo: EPU. 1986.

MORAES, R.; GALIAZZI, M. C. Análise textual discursiva. Ijuí/RS: Editora UNIJUÍ. 2007.

MOUSINHO, S. P.; SILVA, M. B.; BRANDÃO, A. G. A visão de ciência de professores e estudantes de Araruna-PB. In: III Congresso Nacional de Educação, 2016, Natal. Anais [...]. Campina Grande/PB: Editora Realize, 2016.

OLIVEIRA, G. L. Panorama das pesquisas sobre divulgação científica/popularização da ciência no Brasil. Dissertação (Mestrado em Educação em Ciências) - Universidade Federal do Rio Grande. Programa de Pós-Graduação em Educação em Ciências: Química da Vida e Saúde. Rio Grande/RS, 98 p. 2015.

PÉREZ, D. G.; MONTORO, I. F.; ALIS, J. C.; CACHAPUZ, A.; PRAIA, J. Para uma imagem não deformada do trabalho científico. Ciência e Educação. v.7, n.2, p.125-153, 2001.

ROJAS, G. Em dia histórico, cientistas revelam primeira imagem de um buraco negro. Ciência Estadão. 2019. Disponível em: https://ciencia.estadao.com.br/noticias/geral,astronomos-revelam-primeira-imagem-deum-buraco-negro,70002786184. Acesso em: 29 jun. 2019.

ROSA, S. E.; AULER, D. Não neutralidade da ciência-tecnologia: problematizando silenciamentos em práticas educativas CTS. Alexandria: revista de educação em ciência e tecnologia, v. 9, n. 2, p. 203-231, 2016.

SOUZA, P. H. R.; ROCHA, M. B. O caráter híbrido dos textos de divulgação científica inseridos em livros didáticos. Ciência \& Educação (Bauru). v. 24, n. 4, p. 1043-1063, 2018.

STRIEDER, R. B. Abordagens CTS na educação científica no Brasil: sentidos e perspectivas. 2012. 283 p. Tese (Doutorado em Ensino de Ciências) - Universidade de São Paulo, Instituto de Física, Instituto de Química e Instituto de Biociências. Programa de Pós-Graduação Interunidades em Ensino de Ciências. São Paulo, 2012.

TOSAR, B. Assim se 'fotografa' um buraco negro. El País: o jornal global. 2019. Disponível em: https://brasil.elpais.com/brasil/2019/04/10/ciencia/1554906802_123817.html. Acesso em: 29 jun. 2019, 